\title{
Atherosclerotic Change at One Year After Implantation of Endeavor Zotarolimus-Eluting Stent vs. Everolimus-Eluting Stent
}

\author{
Yasuhiro Akazawa, MD; Koshi Matsuo, MD; Yasunori Ueda, MD, PhD; \\ Mayu Nishio, MD, PhD; Akio Hirata, MD, PhD; Mitsutoshi Asai, MD, PhD; \\ Takayoshi Nemoto, MD; Mitsuru Wada, MD; Ayaka Murakami, BSc; \\ Kazunori Kashiwase, MD, PhD; Kazuhisa Kodama, MD, PhD
}

\begin{abstract}
Background: Atherosclerosis progression is thought to be one of the mechanisms of late stent failure. Atherosclerosis progression is detected as yellow plaque formation on angioscopy. Cypher sirolimus-eluting stent has been reported to accelerate atherosclerosis progression, but the influence of Endeavor zotarolimus-eluting stent (EndeavorZES) or Xience everolimus-eluting stent (Xience-EES) on atherosclerosis has not been clarified. Therefore, we examined the serial changes in extent of atherosclerosis after the implantation of Endeavor-ZES or Xience-EES.

Methods and Results: Consecutive patients who received implantation of Endeavor-ZES ( $n=25$ ) or Xience-EES $(n=30)$ at de novo lesion of native coronary artery and who had successful angioscopy immediately after stent implantation (baseline) and at 1-year follow-up were included in the study. Change in the maximum yellow color grade (grade 0-3) of the stented segment from baseline to follow-up was examined and was compared between Endeavor-ZES and Xience-EES. The maximum yellow color grade decreased significantly from baseline to follow-up in Endeavor-ZES (1.6 \pm 1.1 vs. $0.4 \pm 0.8, P<0.001)$, but it did not change in Xience-EES $(1.7 \pm 1.0$ vs. $1.4 \pm 0.7, P=0.23)$. Although the maximum yellow color grade was not different between Endeavor-ZES and Xience-EES at baseline $(P=0.72)$, it was significantly lower in Endeavor-ZES than in Xience-EES at follow-up $(P<0.001)$.
\end{abstract}

Conclusions: Atherosclerosis evaluated by yellow color of the plaque was significantly reduced at 1 year after Endeavor-ZES implantation, but was not changed after Xience-EES implantation. (Circ J 2014; 78: 1428-1436)

Key Words: Angioscopy; Drug-eluting stent; Neointima; Yellow plaque

D rug-eluting stent (DES) compared with bare metal stent (BMS) has reduced early target lesion revascularization (TLR) through an inhibitory effect on neointima hyperplasia but has increased the risk of stent thrombosis and TLR after 1 year (ie, late stent failure). ${ }^{1}$ Although the incidence of stent thrombosis and TLR appeared reduced in the newer DES than the first-generation DES, ${ }^{2-8}$ the mechanisms of late stent failure are not well understood.

\section{Editorial $\mathrm{p} 1325$}

Angioscopy, as a tool of macroscopic pathology in living patients, can be used to evaluate the extent of atherosclerosis according to the presence of yellow plaque. Yellow plaque, especially that of high yellow color grade, is regarded as vulnerable plaque and has been associated with future coronary events. ${ }^{9-12}$ Neoatherosclerosis or atherosclerosis progression has been reported as a cause of late stent failure in both DES and BMS. ${ }^{13}$ Cypher sirolimus-eluting stent (Cypher-SES) has been reported to accelerate yellow plaque formation. ${ }^{14}$ The influence of Endeavor zotarolimus-eluting stent (Endeavor-ZES) or Xience everolimus-eluting stent (Xience-EES) on atherosclerosis progression, however, has not been clarified. Therefore, we examined the serial changes of yellow plaque appearance after the implantation of Endeavor-ZES or Xience-EES.

\section{Methods}

\section{Study Design}

This was a single-center serial follow-up study to examine the changes in the yellow color of the stent-implanted segment from baseline to 1-year follow-up after the implantation of

Received January 26, 2014; revised manuscript received February 26, 2014; accepted February 27, 2014; released online April 8, 2014 Time for primary review: 17 days

Cardiovascular Division, Osaka Police Hospital, Osaka, Japan

Mailing address: Yasunori Ueda, MD, PhD, FACC, FESC, FJCC, Cardiovascular Division, Osaka Police Hospital, 10-31 Kitayama-cho, Tennoji-ku, Osaka 543-0035, Japan. E-mail: ueda@oph.gr.jp

ISSN-1346-9843 doi:10.1253/circj.CJ-14-0085

All rights are reserved to the Japanese Circulation Society. For permissions, please e-mail: cj@j-circ.or.jp 


\begin{tabular}{lccc}
\hline Table 1. Patient Characteristics & & & \\
No. patients & Endeavor-ZES & Xience-EES & P-value \\
Male & 25 & 30 & 0.62 \\
Age (years) & $21(84)$ & $25(83)$ & 0.32 \\
Risk factor & $68 \pm 8$ & $66 \pm 8$ & \\
$\quad$ Diabetes mellitus & & & 0.47 \\
Hypertension & $12(48)$ & $13(43)$ & 0.12 \\
Hypercholesterolemia & $21(84)$ & $29(97)$ & 0.23 \\
Current smoking & $22(88)$ & $23(77)$ & \\
Diagnosis for stenting & $0(0)$ & $0(0)$ & 0.57 \\
ACS & & & \\
Non-ACS & $3(12)$ & $3(10)$ & 0.29 \\
Target vessel & $22(88)$ & $27(90)$ & \\
LAD & & & \\
LCX & $10(40)$ & $17(57)$ & \\
RCA & $1(4)$ & $6(20)$ & 0.60 \\
Medication & $14(56)$ & $7(23)$ & 0.57 \\
Statin & & & 0.20 \\
Aspirin & $19(76)$ & $23(77)$ & 0.20 \\
Clopidogrel/Ticlopidine & $22(88)$ & $27(90)$ & 0.20 \\
ARB/ACEI & $23(92)$ & $30(100)$ & $19(63)$ \\
$\beta$-blocker & $8(32)$ & $14(47)$ & \\
\hline
\end{tabular}

Data given as mean \pm SD or $\mathrm{n}(\%)$.

ACEI, angiotensin-converting enzyme inhibitor; ACS, acute coronary syndrome; ARB, angiotensin receptor blocker; EES, everolimus-eluting stent; LAD, left anterior descending coronary artery; LCX, left circumflex coronary artery; $\mathrm{RCA}$, right coronary artery; ZES, zotarolimus-eluting stent.

\begin{tabular}{|lccc|}
\hline Table 2. Lesion and Procedural Characteristics & & & \\
No. target lesions & Endeavor-ZES & Xience-EES & P-value \\
Angiographic stenosis (\%) & 25 & 30 & \\
$\quad$ Before intervention & & & 0.18 \\
After intervention & $70.3 \pm 17.7$ & $64.1 \pm 15.9$ & 0.89 \\
At follow-up & $11.7 \pm 8.8$ & $12.0 \pm 7.3$ & 0.03 \\
TIMl flow grade (0/1/2/3), n & $21.3 \pm 12.1$ & $15.2 \pm 6.7$ & \\
Before intervention & & & 0.46 \\
After intervention & $2 / 1 / 4 / 18$ & $3 / 0 / 2 / 25$ & - \\
At follow-up & $0 / 0 / 0 / 25$ & $0 / 0 / 0 / 30$ & - \\
Stent size (mm) & $0 / 0 / 0 / 25$ & $0 / 0 / 0 / 30$ & $<0.001$ \\
Total stent length (mm) & $3.2 \pm 0.3$ & $2.8 \pm 0.3$ & 0.20 \\
Maximum inflation pressure (atm) & $24.3 \pm 13.2$ & $30.3 \pm 20.7$ & 0.49 \\
Procedural success (\%) & $17 \pm 4$ & $17.7 \pm 3$ & - \\
\hline
\end{tabular}

Data given as mean $\pm \mathrm{SD}$ or $\mathrm{n}(\%)$.

TIMI, Thrombolysis in Myocardial Infarction. Other abbreviations as in Table 1.

Endeavor-ZES (Endeavor stent; Medtronic, Minneapolis, MN, USA) or Xience-EES (Xience V; Abbott Vascular, Santa Clara, CA, USA) using angioscopy. The change of maximum yellow color grade from baseline to follow-up was examined for Endeavor-ZES and Xience-EES, respectively, and was compared between Endeavor-ZES and Xience-EES.

One-year follow-up catheterization was encouraged for all patients who received coronary intervention, but it was not performed when (1) the patient had renal dysfunction; or (2) informed consent was not obtained. Baseline and follow-up angioscopy was encouraged for all patients who received DES implantation, but it was not performed when (1) an angio- scopic specialist was not available; (2) there was not adequate time for the examination; or (3) informed consent was not obtained. We have a registry of all patients who undergo angioscopy. From this registry, we retrospectively analyzed for this study the consecutive patients who received implantation of Endeavor-ZES or Xience-EES at de novo lesion of native coronary artery and who had successful angioscopy immediately after stent implantation (baseline) and at 1-year followup (between May 2010 and July 2012).

During this period, Endeavor-ZES was implanted in 197 patients, angioscopy immediately after implantation was performed in 61 patients, and follow-up angioscopy was done in 

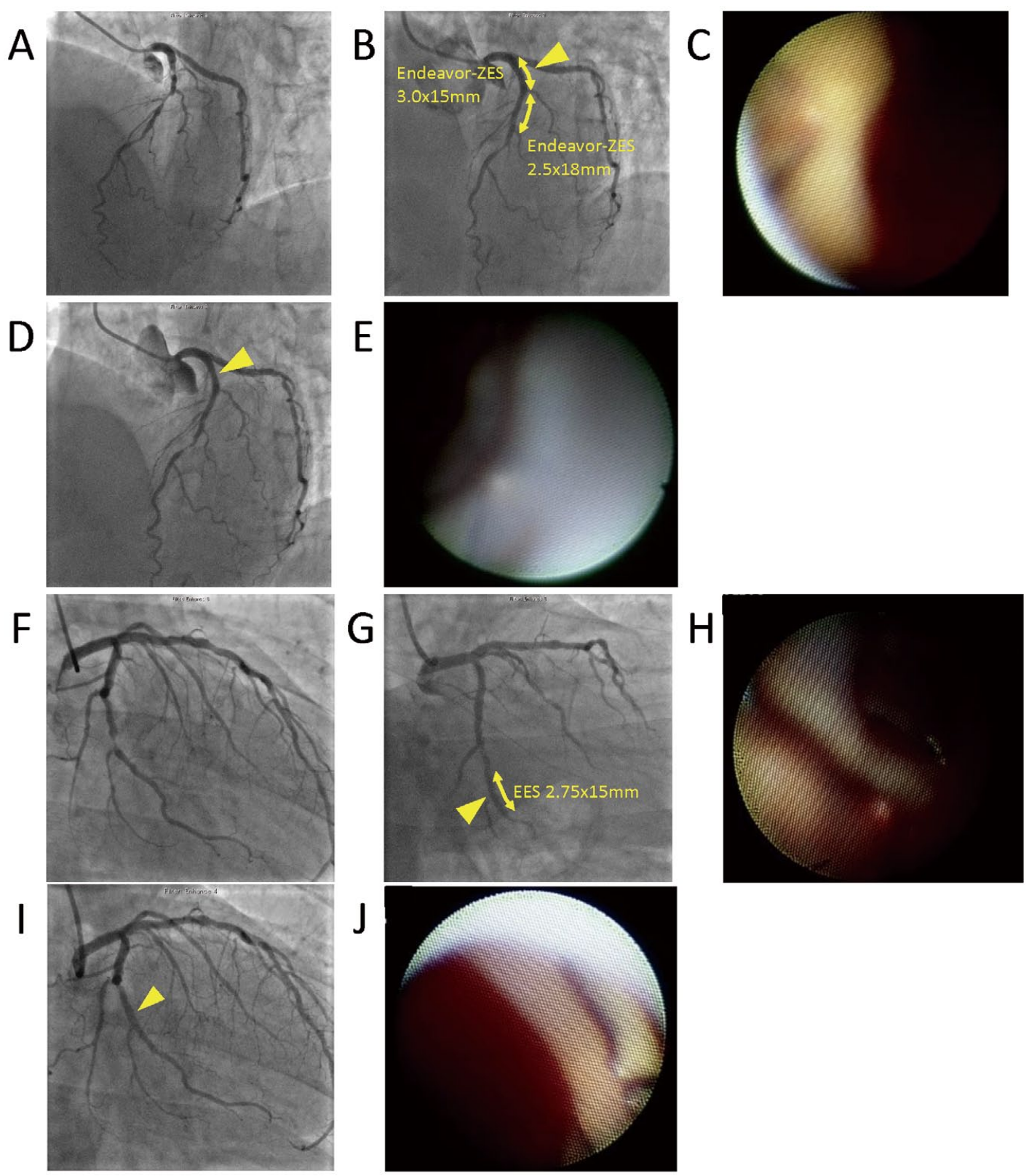

Figure 1. Representative cases of Endeavor zotarolimus-eluting stent (Endeavor-ZES) and Xience everolimus-eluting stent (Xience-EES). (A) A 73-year-old female patient with stable effort angina had severe stenosis in the proximal left anterior descending coronary artery. (B) She underwent implantation of Endeavor-ZES. (C) Angioscopy showed grade 2 yellow plaque behind the stent immediately after stenting. (D) At 1-year follow-up, angiogram indicated no restenosis. (E) The stent was completely covered (grade 2) by white thick neointima, and yellow plaque was not observed. (F) A 60-year-old male patient with silent myocardial ischemia had severe stenosis in the distal left circumflex coronary artery. (G) He underwent implantation of Xience-EES. (H) Angioscopy showed grade 2 yellow plaque behind the stent immediately after stenting. (I) At 1-year follow-up, angiogram indicated no restenosis. (J) Although the stent had grade 1 neointima coverage, the yellow plaque was still observed behind the stent. Yellow line with arrows, site of stent implantation; yellow arrowhead, site of angioscopic observation.

25 patients without re-intervention before follow-up; and Xience-EES was implanted in 232 patients, angioscopy immediately after implantation was done in 83 patients, and follow-up angioscopy was carried out in 30 patients without re-intervention before follow-up. The patients who received re-intervention of the target lesion before planned follow-up ( 2 patients for Endeavor-ZES and 1 patient for Xience-EES) were not included, because we focused on clarifying the angioscopic characteristics of the stented lesion in the patients without early stent failure before 1-year follow-up.

Catheterization was performed via the femoral, brachial, or radial artery approach using a 6-Fr or 7-Fr sheath and catheters. Coronary angiogram was recorded using the Innova Cardiovascular imaging system (GE Healthcare Japan, Tokyo, Japan); 


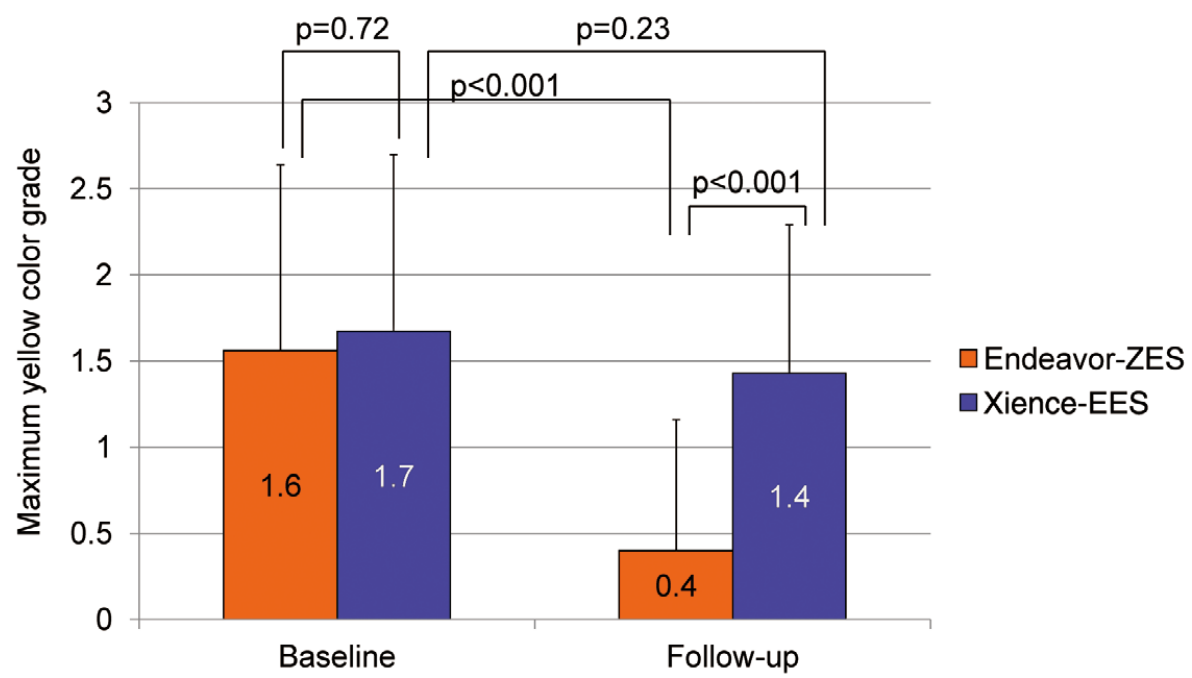

Figure 2. Comparison of maximum yellow color grade. The maximum yellow color grade decreased significantly from baseline to follow-up in Endeavor zotarolimus-eluting stent (Endeavor-ZES), but it was not changed in Xience everolimus-eluting stent (Xience-EES). Although the maximum yellow color grade was not different between Endeavor-ZES and Xience-EES at baseline, it was significantly lower in Endeavor-ZES than in Xience-EES at follow-up. Therefore, the degree of reduction in yellow color grade was larger in Endeavor-ZES than in Xience-EES.

and quantitative coronary angiographic analysis was done with the system. All patients were taking aspirin $100 \mathrm{mg} /$ day and ticlopidine $500 \mathrm{mg} /$ day or clopidogrel $75 \mathrm{mg} /$ day (dual antiplatelet therapy) throughout the study period. GPIIb/IIIa inhibitors were not used for any patient, because they were not approved in Japan for clinical use. Hypertension was defined as blood pressure $>140 / 90 \mathrm{mmHg}$ or the use of anti-hypertensive drugs. Diabetes mellitus was defined as fasting blood glucose $>126 \mathrm{mg} / \mathrm{dl}$ or the use of oral drugs for diabetes mellitus or insulin therapy. Acute coronary syndrome (ACS) includes acute myocardial infarction with/without ST elevation defined by the Joint European Society of Cardiology/American College of Cardiology Committee, and unstable angina defined according to the Braunwald classification. This study was approved by the Osaka Police Hospital Ethics Committee. Written informed consent was obtained from all enrolled patients.

\section{Angioscopy}

The angioscope RX-3310A and MV-5010A (Machida, Tokyo, Japan) and optic fiber DAG-2218LN (Machida) were used. Angioscopic observation of stented lesions was done while blood was cleared away from view by the injection of $3 \%$ dextran-40 as we have previously reported..$^{15}$ Yellow color was classified into 4 grades ( 0 , white; 1 , slight yellow; 2 , yellow; and 3 , intensive yellow) compared with standard colors as we have previously reported. ${ }^{9,10}$ Neointima coverage was classified into 3 grades $(0$, no coverage; 1 , poor coverage; 2 , complete coverage) as we have previously reported. ${ }^{14,16}$ Thrombus was defined as white or red material that had cotton-like or ragged appearance or that presented fragmentation with or without protrusion into the lumen or adherent to the lumen surface. Maximum and minimum neointima coverage grade, maximum yellow color grade, and presence or absence of thrombus was determined for each stented lesion at baseline and at follow-up. The heterogeneity score was defined as maximum-minimum neointima coverage grade to evaluate the heterogeneity of the coverage. Two angioscopy specialists evaluated the angioscopic images blinded to patient characteristics. In the case of disagreement, a third reviewer served as an arbitrator. The inter- and intra-observer reproducibility for the interpretation of angioscopic images was $95 \%$ and $95 \%$ for stent coverage, $85 \%$ and $95 \%$ for plaque color, and $90 \%$ and $100 \%$ for thrombus, respectively.

\section{Statistical Analysis}

Continuous data are presented as mean \pm SD. Comparison of maximum yellow color grade between baseline and follow-up was performed by Wilcoxon signed rank test. Comparison between groups was done using unpaired student t-test, chi-squared test, or Mann-Whitney test. To determine the significant factors associated with maximum yellow color grade at follow-up, multivariate stepwise linear regression analysis was done using stent type, age, gender, hypertension, hypercholesterolemia, diabetes mellitus, stenting for ACS, statin use, maximum yellow color grade at baseline, and minimum neointima coverage grade at follow-up as independent variables. $\mathrm{P}<0.05$ was regarded as statistically significant. All analysis was carried out using SPSS 16.0 J for Windows (SPSS, Chicago, IL, USA).

\section{Results}

\section{Patients and Lesion Characteristics}

Included were 25 patients ( 25 lesions) for Endeavor-ZES and 30 patients (30 lesions) for Xience-EES. Follow-up interval was $380 \pm 53$ days for Endeavor-ZES and $375 \pm 33$ days for Xience-EES. There was no significant difference in patient, lesion, or procedural characteristics between the EndeavorZES and Xience-EES groups (Tables 1,2), except that stent diameter was larger and angiographic stenosis was more severe at follow-up in the Endeavor-ZES than in the Xience-EES group. Type of ACS was unstable angina in all cases, and no patients with acute myocardial infarction were included. Rep- 


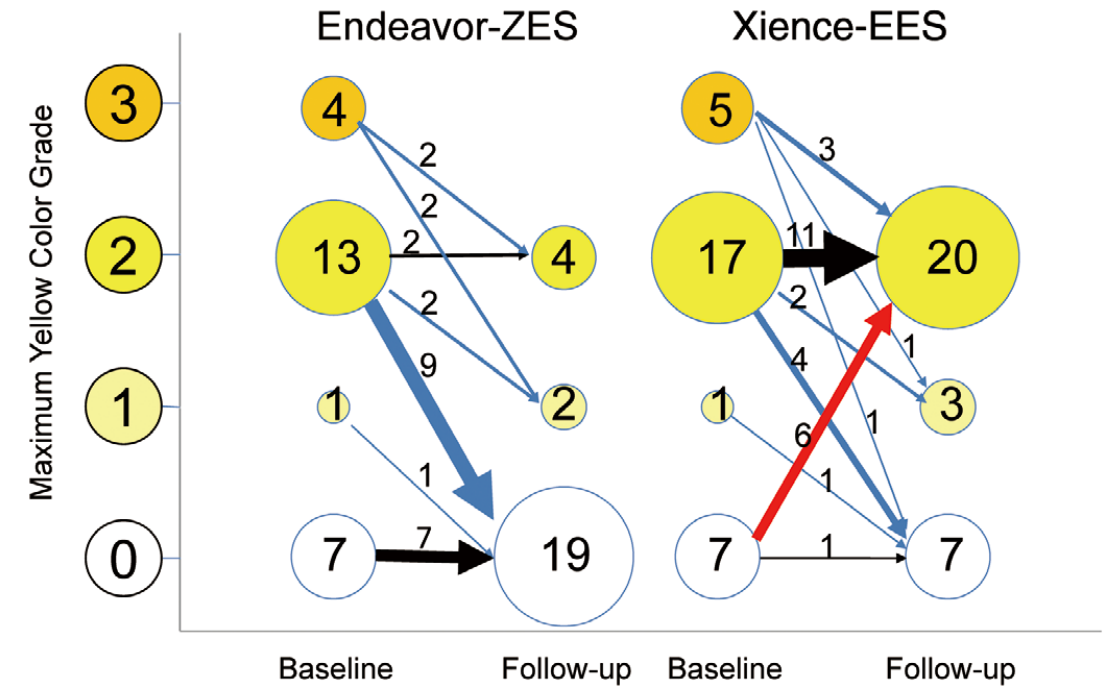

Figure 3. Change in maximum yellow color grade from baseline to follow-up for each patient. The yellow color grade generally decreased in Endeavor zotarolimus-eluting stent (Endeavor-ZES). Xience-EES, Xience everolimus-eluting stent.

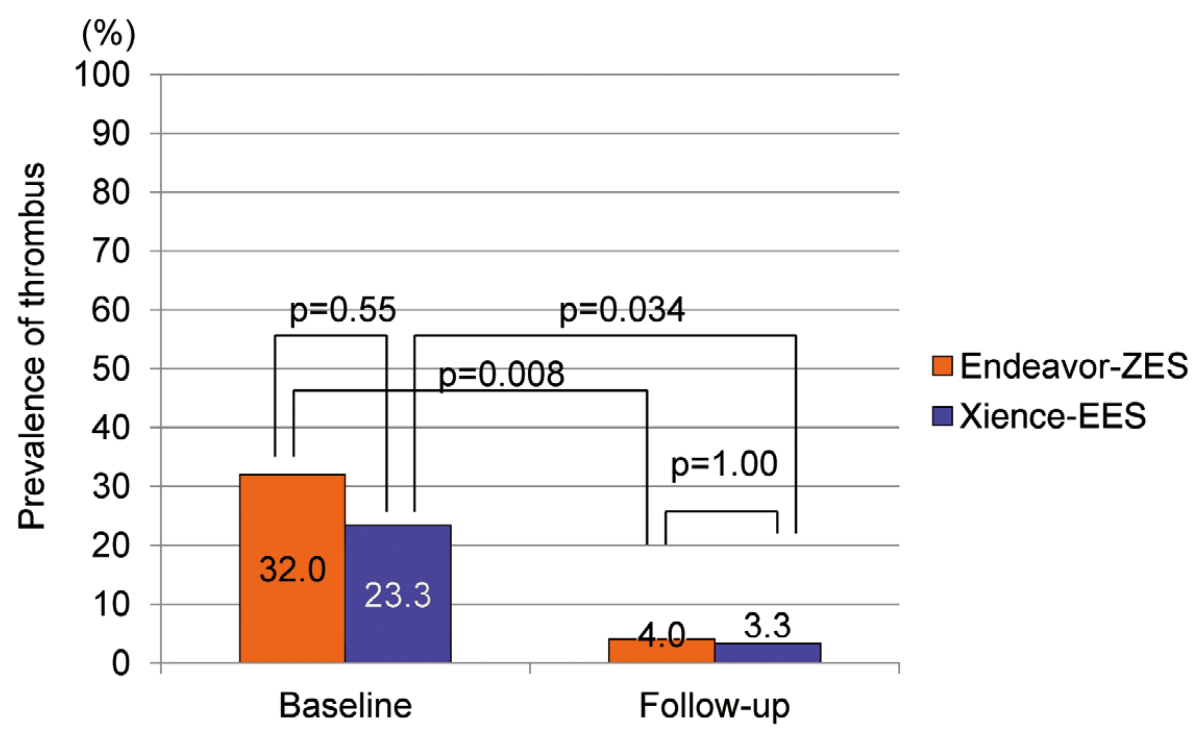

Figure 4. Prevalence of thrombus decreased significantly from baseline to follow-up in both stents and was not different between the stents. Xience-EES, Xience everolimus-eluting stent; Endeavor-ZES, Endeavor zotarolimus-eluting stent.

resentative cases of Endeavor-ZES and Xience-EES are shown in Figure 1.

\section{Angioscopic Findings}

The maximum yellow color grade (Figure 2) decreased significantly from baseline to follow-up in Endeavor-ZES (1.6 \pm 1.1 vs. $0.4 \pm 0.8, \mathrm{P}<0.001)$, but it did not change in Xience-EES ( $1.7 \pm 1.0$ vs. $1.4 \pm 0.7, \mathrm{P}=0.23$ ). Although the maximum yellow color grade was not different between Endeavor-ZES and Xience-EES at baseline (1.6 \pm 1.1 vs. $1.7 \pm 1.0, \mathrm{P}=0.72)$, it was lower in Endeavor-ZES than in Xience-EES at follow-up $(0.4 \pm 0.8$ vs. $1.4 \pm 0.7, \mathrm{P}<0.001)$. Therefore, the degree of reduction in the maximum yellow color grade was larger in Endeavor-ZES than in Xience-EES (1.2 \pm 1.0 vs. $0.2 \pm 1.4$,
$\mathrm{P}=0.007)$. When we analyzed only the patients who received $3.0-\mathrm{mm}$ stent, the degree of reduction in maximum yellow color grade was still larger in Endeavor-ZES than in XienceEES $(1.0 \pm 1.0$ vs. $-0.1 \pm 1.3, \mathrm{P}=0.03)$. The changes in maximum yellow color grade are shown in Figure 3 .

The prevalence of thrombus decreased significantly from baseline to follow-up in both stents and was not different between the stents (Figure 4). The maximum (1.8 \pm 0.4 vs. $1.2 \pm 0.4, \mathrm{P}<0.001)$ and minimum $(1.3 \pm 0.5$ vs. $0.8 \pm 0.4, \mathrm{P}=0.001)$ coverage grade was significantly better in Endeavor-ZES than in Xience-EES (Figure 5). The heterogeneity score was not different between Endeavor-ZES and Xience-EES (0.52 \pm 0.59 vs. $0.40 \pm 0.50, \mathrm{P}=0.42$ ). Thrombus was detected only in 2 patients at follow-up: 1 patient with Endeavor-ZES had maxi- 


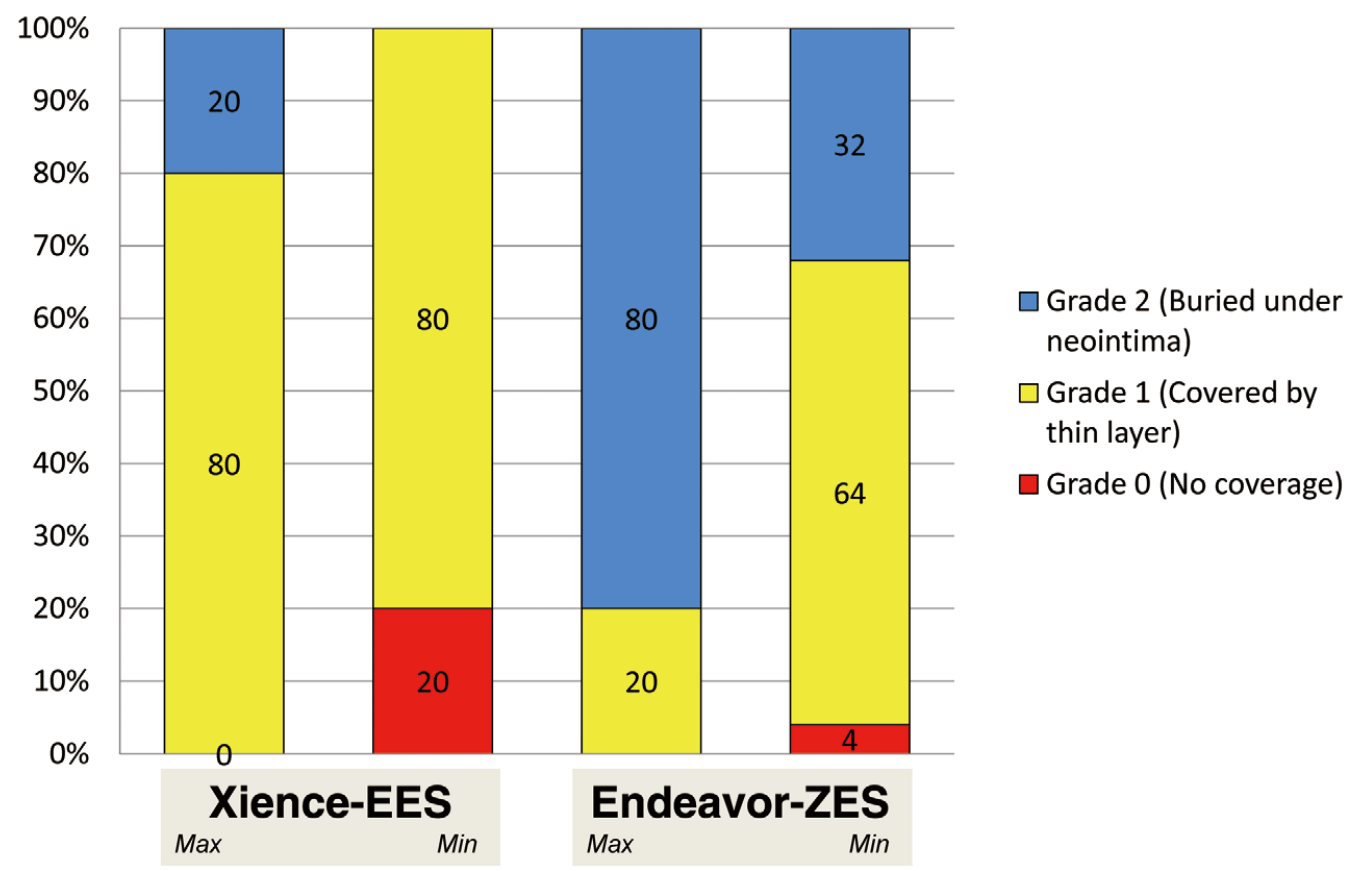

Figure 5. Distribution of minimum and maximum neointima coverage grade at follow-up. The maximum and minimum coverage grade was significantly better in Endeavor zotarolimus-eluting stent (Endeavor-ZES) than in Xience everolimus-eluting stent (Xience-EES). Major neointima coverage grade was grade 2 in Endeavor-ZES and was grade 1 in Xience-EES.
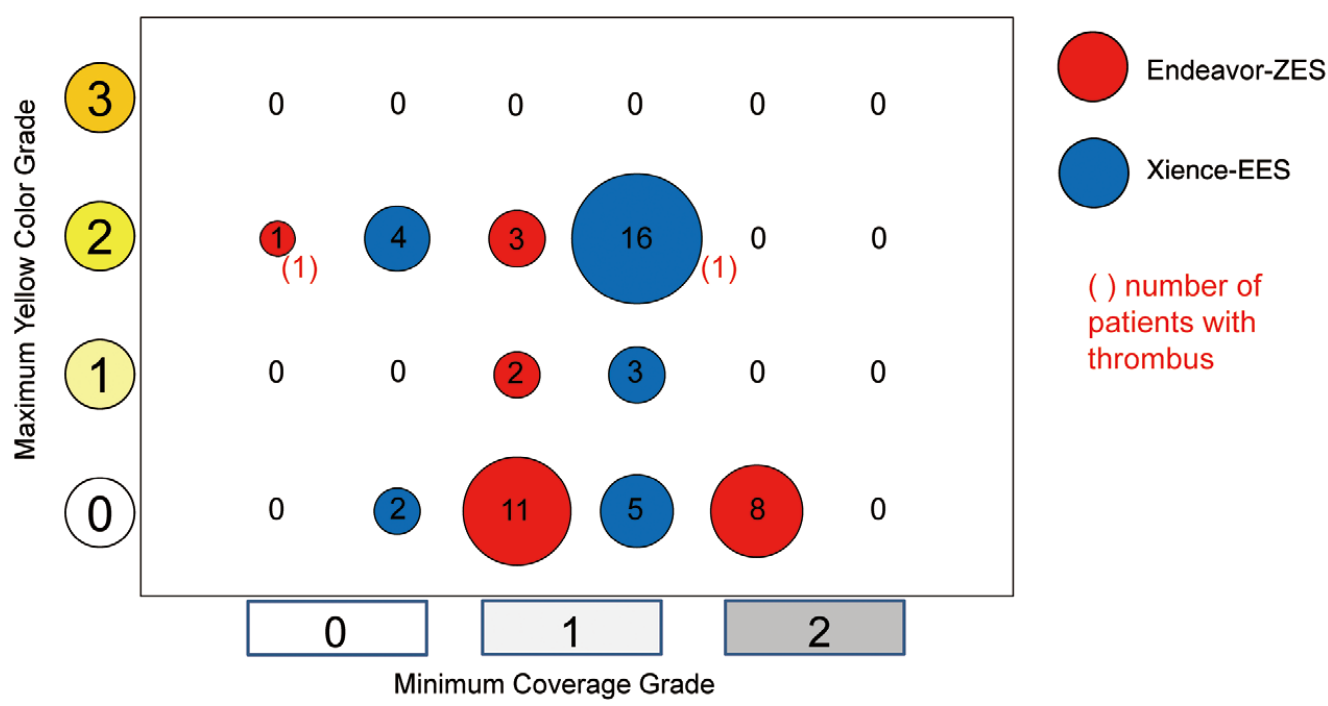

( ) number of patients with thrombus

Figure 6. Combination of maximum yellow color grade and minimum coverage grade with or without the presence of thrombus. Thrombus was detected only in 2 patients at follow-up: 1 patient with Endeavor zotarolimus-eluting stent (Endeavor-ZES) who had maximum yellow color grade 2 and minimum coverage grade 0 ; and 1 patient with Xience everolimus-eluting stent (Xience-EES) who had maximum yellow color grade 2 and minimum coverage grade 1 .

mum yellow color grade 2 and minimum coverage grade 0 , and 1 patient with Xience-EES had maximum yellow color grade 2 and minimum coverage grade 1 (Figure 6).
Contributing Factors to Maximum Yellow Grade at Follow-up On multivariate stepwise linear regression analysis only stent type (Xience-EES=0, Endeavor-ZES=1) was a significant contributor to maximum yellow color grade at follow-up $(B=-1.03$; 
95\% confidence interval, -1.48 to $-0.59 ; \mathrm{P}<0.001$ ), when stent type, age, gender, hypertension, hypercholesterolemia, diabetes mellitus, stenting for ACS, statin use, maximum yellow color grade at baseline, and minimum neointima coverage grade at follow-up were included as independent variables.

\section{Discussion}

The maximum yellow color grade did not change from baseline to 1-year follow-up when Xience-EES was implanted, but it decreased significantly when Endeavor-ZES was implanted. In other words, atherosclerosis evaluated by yellow plaque was significantly reduced at 1 year after Endeavor-ZES implantation, while it was not changed after Xience-EES implantation.

\section{Delayed Healing as Cause of Late Stent Failure}

The incidence of thrombus at follow-up in Cypher-SES has been reported to be as high as $10-40 \%$ according to previous studies. ${ }^{14,16-23}$ This delayed healing or lack of healing with high frequency of thrombogenesis has been regarded as one of the possible mechanisms for thrombotic occlusion or stenosis progression in the first-generation DES. As shown in the present study, however, both Endeavor-ZES and Xience-EES had very low incidence of thrombus, and therefore, delayed healing would not be a major mechanism of late stent failure in those stents. The presence of thrombus has been associated with high yellow color grade and low neointima coverage grade. ${ }^{14}$ Indeed, thrombus was detected in 2 patients with grade 2 maximum yellow color grade and grade $0 / 1$ minimum coverage grade in the present study, but the incidence of thrombus was similarly low in both Endeavor-ZES and Xience-EES regardless of the different yellow color grade and different neointima coverage grade. Angioscopy can classify neointima coverage only approximately into 3 grades, and angioscopically poor coverage (grade 0 and 1) may or may not have thin but mature neointima that can prevent thrombus formation. Therefore, it would be reasonable to suggest that Xience-EES has very thin but good neointima that can prevent thrombus formation.

\section{Neo/Atherosclerosis Progression as Cause of Late Stent Failure} Development of atherosclerotic plaque and its disruption is known as a cause of ACS after BMS implantation, but it usually takes approximately 5-10 years for the formation of atherosclerotic yellow plaque in the non-atherosclerotic (fibrous) white thick neointima formed over BMS and the resultant development of ACS due to its disruption. ${ }^{11}$ Development of neoatherosclerosis has also been reported as a cause of very late stent thrombosis ${ }^{24}$ and of restenosis after DES implantation. ${ }^{25}$ In a porcine model study, long-term inhibition of neointima hyperplasia after polymer-based SES was not maintained, partly because of persistent inflammatory stimuli and subsequent cellular proliferation. ${ }^{26}$ Higo et al reported for the first time in living humans that Cypher-SES accelerated the formation of atherosclerotic yellow neointima at 10 months, with intramural thrombus being more frequently detected in the newly formed yellow neointima. ${ }^{14} \mathrm{~A}$ recent histopathologic study by Nakazawa et al confirmed the presence of neoatherosclerosis in the neointima after BMS and DES implantation, with a shorter time to develop neoatherosclerosis for DES than BMS. ${ }^{13}$ Although Cypher-SES accelerates the progression of atherosclerosis, as we have previously demonstrated by the increase of yellow color, and Endeavor-ZES causes the stabilization of atherosclerosis, as shown in the present study by the reduction of yellow color, Xience-EES did not significantly cause progression of atherosclerosis in the present study, given that the yellow color was not changed. The reduction of yellow color by Endeavor-ZES would be caused mainly by the formation of thick non-atherosclerotic fibrous white neointima, as in BMS. The formation of thick non-atherosclerotic fibrous white neointima over atherosclerotic lesions plays a role in sealing and shielding that makes the vulnerable plaque stable. In contrast, Xience-EES had very thin neointima that could not seal and shield the yellow plaque under the stent. Another important finding is that Xience-EES did not accelerate the formation of yellow plaque like Cypher-SES. Yellow plaque formation is accelerated by various coronary risk factors as a process of atherosclerosis progression, and is regressed by various treatments such as statins. ${ }^{27,28}$ Therefore, in combination with these systemic factors and medications, the characteristics of DES may influence the formation of yellow plaques in the stent-implanted segments. We believe that the presence of in-stent yellow plaque at 1-year follow-up, resulting from the combination of these mechanisms, would be a risk for future stent failure after 1 year. Indeed, statin use has been associated with lower risk of late TLR after Cypher-SES implantation. ${ }^{29}$ It has been shown that the coronary segment with peri-stent contrast staining, which is known as a predictor of late stent thrombosis after DES implantation, frequently has yellow plaque $(82 \%)$ and thrombus $(64 \%) .^{30}$

According to the results of clinical trials with long-term follow-up to 5 years available in previous reports or at the website ClinicalTrial.gov, TLR at 1 and 5 years are $4.9 \%$ and $9.4 \%$ in Cypher-SES; ${ }^{31,32} 4.4 \%$ and $9.1 \%$ in Taxus paclitaxel-eluting stent (Taxus-PES); ${ }^{33,34} 5.9 \%$ and 7.5\% in Endeavor-ZES; ${ }^{35,36}$ and $3.4 \%$ and $8.9 \%$ in Xience-EES. ${ }^{37}$ Therefore, the very late stent failure as shown by the yearly TLR between 1 and 5 years is $1.1 \%$ year, $1.2 \%$ /year, $0.4 \%$ /year, and $1.4 \%$ /year in CypherSES, Taxus-PES, Endeavor-ZES, and Xience-EES, respectively, which appears to be lower in Endeavor-ZES than in other DES, although this is not the result of direct head-to-head comparison. A recent report clarified that, in the ENDEAVOR III trial, although higher angiographic restenosis was observed in Endeavor-ZES than in Cypher-SES in the primary results reported for the 9-month follow-up, cumulative outcomes through 5 years showed that the composite endpoint of main adverse coronary event and the important components of death, as well as cardiac death and myocardial infarction, favored treatment with Endeavor-ZES compared with CypherSES. ${ }^{3}$ Furthermore, despite early difference in angiographic outcome, rates of clinical restenosis beyond 9-month followup remained stable with Endeavor-ZES compared with CypherSES, resulting in similar late-term efficacy as measured by the need for TLR. The higher incidence of late-term stent failure in Cypher-SES than in Endeavor-ZES may possibly be explained by the fact that Cypher-SES accelerates the progression of yellow plaque and Endeavor-ZES induces regression of the yellow color. Judging from the present results, the stability of the stented segments with Xience-EES may be between those of Endeavor-ZES and Cypher-SES. The difference in longterm clinical outcome between Xience-EES and EndeavorZES may not be clarified without randomized trials.

\section{Angioscopic Findings and Future DES Failure}

According to the accumulated findings described here, we believe that the extent of atherosclerosis in the DES-implanted segment as shown by its yellow color would be associated with future DES failure. In order to demonstrate that the angioscopic findings at 1-year follow-up would be associated with future DES failure, we are now performing a singlecenter prospective study (DESNOTE study: Detect the Event 
of very late Stent failure from the drug-eluting stent NOT well covered by nEointima determined on angioscopy). All patients with successful angioscopy at planned 1-year follow-up after DES implantation without any event of DES failure before the follow-up have been enrolled since 2004 and are clinically followed up at the outpatient clinic. Angioscopic findings are yellow color, neointima coverage, and thrombus at the DESimplanted segment. DES failure is defined as (1) cardiac death; (2) myocardial infarction or unstable angina at the target stent; or (3) TLR.

\section{Study Limitations}

Although we have demonstrated the changes in yellow color after the implantation of Endeavor-ZES and Xience-EES, it remains to be clarified whether the yellow color is a surrogate endpoint of future stent failure. Therefore, the present results do not indicate the clinical superiority or inferiority of the examined DES. Although patient characteristics were generally similar between the Endeavor-ZES and Xience-EES groups, they were not completely matched, because this was not a randomized trial. Although there was a significant difference in stent diameter between the groups, the degree of reduction in maximum yellow color grade was still larger in EndeavorZES than in Xience-EES when we included 3.0-mm stent alone. Although the atherosclerotic change up to 1 year has been clarified in the present study, the change thereafter should be clarified in further investigations. Only a small percentage of all patients who received Endeavor-ZES or Xience-EES were included in the present analysis. Possible selection bias would be that the patients with renal dysfunction and those with small or tortuous coronary artery not suitable for angioscopy were not included in the present analysis.

\section{Conclusions}

Atherosclerosis evaluated by yellow color of the plaque was significantly reduced at 1 year after Endeavor-ZES implantation, but it was not changed after Xience-EES implantation.

\section{Disclosures}

The authors have no conflicts of interest.

\section{References}

1. Daemen J, Wenaweser P, Tsuchida K, Abrecht L, Vaina S, Morger $\mathrm{C}$, et al. Early and late coronary stent thrombosis of sirolimus-eluting and paclitaxel-eluting stents in routine clinical practice. Lancet 2007; 369: $667-678$.

2. Eisenstein EL, Wijns W, Fajadet J, Mauri L, Edwards R, Cowper PA, et al. Long-term clinical and economic analysis of the Endeavor drug-eluting stent versus the Driver bare-metal stent: 4-year results from the ENDEAVOR II trial (Randomized Controlled Trial to Evaluate the Safety and Efficacy of the Medtronic AVE ABT-578 Eluting Driver Coronary Stent in De Novo Native Coronary Artery Lesions). JACC Cardiovasc Interv 2009; 2: 1178-1187.

3. Kandzari DE, Mauri L, Popma JJ, Turco MA, Gurbel PA, Fitzgerald PJ, et al. Late-term clinical outcomes with zotarolimus- and sirolimus-eluting stents. 5-year follow-up of the ENDEAVOR III (A Randomized Controlled Trial of the Medtronic Endeavor Drug [ABT578] Eluting Coronary Stent System Versus the Cypher SirolimusEluting Coronary Stent System in De Novo Native Coronary Artery Lesions). JACC Cardiovasc Interv 2011; 4: 543-550.

4. Leon MB, Kandzari DE, Eisenstein EL, Anstrom KJ, Mauri L, Cutlip DE, et al. Late safety, efficacy, and cost-effectiveness of a zotarolimus-eluting stent compared with a paclitaxel-eluting stent in patients with de novo coronary lesions: 2-year follow-up from the ENDEAVOR IV trial (Randomized, Controlled Trial of the Medtronic Endeavor Drug [ABT-578] Eluting Coronary Stent System Versus the Taxus Paclitaxel-Eluting Coronary Stent System in De Novo Native Coronary Artery Lesions). JACC Cardiovasc Interv 2009; 2: $1208-$
1218

5. Garg S, Serruys P, Onuma Y, Dorange C, Veldhof S, Miquel-Hébert $\mathrm{K}$, et al. 3-year clinical follow-up of the XIENCE V everolimuseluting coronary stent system in the treatment of patients with de novo coronary artery lesions: The SPIRIT II trial (Clinical Evaluation of the Xience V Everolimus Eluting Coronary Stent System in the Treatment of Patients with de novo Native Coronary Artery Lesions). JACC Cardiovasc Interv 2009; 2: 1190-1198.

6. Stone GW, Midei M, Newman W, Sanz M, Hermiller JB, Williams $\mathrm{J}$, et al. Randomized comparison of everolimus-eluting and paclitaxeleluting stents: Two-year clinical follow-up from the Clinical Evaluation of the Xience V Everolimus Eluting Coronary Stent System in the Treatment of Patients with de novo Native Coronary Artery Lesions (SPIRIT) III trial. Circulation 2009; 119: 680-686.

7. Stone GW, Simonton CA, Sood P, Kereiakes DJ; SPIRIT IV Investigators. Randomized comparison of everolimus- and paclitaxel-eluting stents. 2-year follow-up from the SPIRIT (Clinical Evaluation of the XIENCE V Everolimus Eluting Coronary Stent System) IV trial. J Am Coll Cardiol 2011; 58: 19-25.

8. Onuma Y, Miquel-Hebert K, Serruys PW; SPIRIT II Investigators. Five-year long-term clinical follow-up of the XIENCE V everolimus-eluting coronary stent system in the treatment of patients with de novo coronary artery disease: The SPIRIT II trial. EuroIntervention 2013; 8: $1047-1051$.

9. Ueda Y, Ohtani T, Shimizu M, Hirayama A, Kodama K. Assessment of plaque vulnerability by angioscopic classification of plaque color. Am Heart J 2004; 148: 333-335.

10. Ueda Y, Asakura M, Yamaguchi O, Hirayama A, Hori M, Kodama $\mathrm{K}$. The healing process of infarct-related plaques. Insights from 18 months of serial angioscopic follow-up. J Am Coll Cardiol 2001; 38: $1916-1922$.

11. Yokoyama S, Takano M, Yamamoto M, Inami S, Sakai S, Okamatsu $\mathrm{K}$, et al. Extended follow-up by serial angioscopic observation for bare-metal stents in native coronary arteries: From healing response to atherosclerotic transformation of neointima. Circ Cardiovasc Interv 2009; 2: 205-212.

12. Hasegawa K, Tamai H, Kyo E, Kosuga K, Ikeguchi S, Hata T, et al. Histopathological findings of new in-stent lesions developed beyond five years. Catheter Cardiovasc Interv 2006; 68: 554-558.

13. Nakazawa G, Vorpahl M, Finn AV, Narula J, Virmani R. One step forward and two steps back with drug-eluting-stents: From preventing restenosis to causing late thrombosis and nouveau atherosclerosis. JACC Cardiovasc Imaging 2009; 2: 625-628.

14. Higo T, Ueda Y, Oyabu J, Okada K, Nishio M, Hirata A, et al. Atherosclerotic and thrombogenic neointima formed over sirolimus drugeluting stent: An angioscopic study. JACC Cardiovasc Imaging 2009; 2: $616-624$.

15. Ueda Y, Nanto S, Komamura K, Kodama K. Neointimal coverage of stents in human coronary arteries observed by angioscopy. J Am Coll Cardiol 1994; 23: 341-346.

16. Oyabu J, Ueda Y, Ogasawara N, Okada K, Hirayama A, Kodama K. Angioscopic evaluation of neointima coverage: Sirolimus drug-eluting stent versus bare metal stent. Am Heart J 2006; 152: 1168-1174

17. Kotani J, Awata M, Nanto S, Uematsu M, Oshima F, Minamiguchi $\mathrm{H}$, et al. Incomplete neointimal coverage of sirolimus-eluting stents: Angioscopic findings. J Am Coll Cardiol 2006; 47: 2108-2111.

18. Hara M, Nishino M, Taniike M, Makino N, Kato H, Egami Y, et al. High incidence of thrombus formation at 18 months after paclitaxeleluting stent implantation: Angioscopic comparison with sirolimuseluting stent. Am Heart J 2010; 159: 905-910.

19. Takano M, Yamamoto M, Murakami D, Inami S, Okamatsu K, Seimiya K, et al. Lack of association between large angiographic late loss and low risk of in-stent thrombus: Angioscopic comparison between paclitaxel- and sirolimus-eluting stents. Circ Cardiovasc Interv 2008; 1: 20-27.

20. Takano M, Yamamoto M, Xie Y, Murakami D, Inami S, Okamatsu $\mathrm{K}$, et al. Serial long-term evaluation of neointimal stent coverage and thrombus after sirolimus-eluting stent implantation by use of coronary angioscopy. Heart 2007; 93: 1533-1536.

21. Awata M, Kotani J, Uematsu M, Morozumi T, Watanabe T, Onishi $\mathrm{T}$, et al. Serial angioscopic evidence of incomplete neointimal coverage after sirolimus-eluting stent implantation: Comparison with baremetal stents. Circulation 2007; 116: 910-916.

22. Awata M, Nanto S, Uematsu M, Morozumi T, Watanabe T, Onishi $\mathrm{T}$, et al. Angioscopic comparison of neointimal coverage between zotarolimus- and sirolimus-eluting stents. J Am Coll Cardiol 2008; 52: $789-790$.

23. Awata M, Nanto S, Uematsu M, Morozumi T, Watanabe T, Onishi $\mathrm{T}$, et al. Heterogeneous arterial healing in patients following paclitaxel-eluting stent implantation: Comparison with sirolimus-eluting 
stents. JACC Cardiovasc Interv 2009; 2: 453-458.

24. Finn AV, Joner M, Nakazawa G, Kolodgie F, Newell J, John MC, et al. Pathological correlates of late drug-eluting stent thrombosis: Strut coverage as a marker of endothelialization. Circulation 2007; 115: $2435-2441$.

25. Liistro F, Stankovic G, Di Mario C, Takagi T, Chieffo A, Moshiri S, et al. First clinical experience with a paclitaxel derivate-eluting polymer stent system implantation for in-stent restenosis: Immediate and long-term clinical and angiographic outcome. Circulation 2002; 105: $1883-1886$.

26. Carter AJ, Aggarwal M, Kopia GA, Tio F, Tsao PS, Kolata R, et al. Long-term effects of polymer-based, slow-release, sirolimus-eluting stents in a porcine coronary model. Cardiovasc Res 2004; 63: 617 624.

27. Hirayama A, Saito S, Ueda Y, Takayama T, Honye J, Komatsu S, et al. Qualitative and quantitative changes in coronary plaque associated with atorvastatin therapy. Circ J 2009; 73: 718-725.

28. Okada K, Ueda Y, Takayama T, Honye J, Komatsu S, Yamaguchi O, et al. Influence of achieved low-density lipoprotein cholesterol level with atorvastatin therapy on stabilization of coronary plaques: Subanalysis of the TWINS study. Circ J 2012; 76: 1197-1202.

29. Natsuaki M, Nakagawa Y, Morimoto T, Ono K, Shizuta S, Furukawa $\mathrm{Y}$, et al. Impact of statin therapy on late target lesion revascularization after sirolimus-eluting stent implantation (from the CREDO-Kyoto Registry Cohort-2). Am J Cardiol 2012; 109: 1387-1396.

30. Ishihara T, Awata M, Fujita M, Watanabe T, Iida O, Ishida Y, et al. Angioscopic assessment of peri-stent contrast staining following drugeluting stent implantation. Circ J 2013; 78: 122-127.

31. Holmes DR Jr, Leon MB, Moses JW, Popma JJ, Cutlip D, Fitzgerald PJ, et al. Analysis of 1-year clinical outcomes in the SIRIUS trial: A randomized trial of a sirolimus-eluting stent versus a standard stent in patients at high risk for coronary restenosis. Circulation 2004; 109: $634-640$

32. Weisz G, Leon MB, Holmes DR Jr, Kereiakes DJ, Popma JJ, Teirstein PS, et al. Five-year follow-up after sirolimus-eluting stent implantation results of the SIRIUS (Sirolimus-Eluting Stent in De-Novo Native Coronary Lesions) Trial. J Am Coll Cardiol 2009; 53: 1488 - 1497.

33. Stone GW, Ellis SG, Cox DA, Hermiller J, O'Shaughnessy C, Mann $\mathrm{JT}$, et al. One-year clinical results with the slow-release, polymerbased, paclitaxel-eluting TAXUS stent: The TAXUS-IV trial. Circulation 2004; 109: $1942-1947$.

34. Ellis SG, Stone GW, Cox DA, Hermiller J, O'Shaughnessy C, Mann $\mathrm{T}$, et al. Long-term safety and efficacy with paclitaxel-eluting stents: 5-year final results of the TAXUS IV clinical trial (TAXUS IV-SR: Treatment of De Novo Coronary Disease Using a Single PaclitaxelEluting Stent). JACC Cardiovasc Interv 2009; 2: 1248-1259.

35. Fajadet J, Wijns W, Laarman GJ, Kuck KH, Ormiston J, Münzel T, et al. Randomized, double-blind, multicenter study of the Endeavor zotarolimus-eluting phosphorylcholine-encapsulated stent for treatment of native coronary artery lesions: Clinical and angiographic results of the ENDEAVOR II trial. Circulation 2006; 114: 798-806.

36. Fajadet J, Wijns W, Laarman GJ, Kuck KH, Ormiston J, Baldus S, et al. Long-term follow-up of the randomised controlled trial to evaluate the safety and efficacy of the zotarolimus-eluting driver coronary stent in de novo native coronary artery lesions: Five year outcomes in the ENDEAVOR II study. EuroIntervention 2010; 6: 562-567.

37. Stone GW, Midei M, Newman W, Sanz M, Hermiller JB, Williams $\mathrm{J}$, et al. Comparison of an everolimus-eluting stent and a paclitaxeleluting stent in patients with coronary artery disease: A randomized trial. JAMA 2008; 299: 1903-1913. 